\title{
The effects of differential injection sites of cold saline on transpulmonary thermodilution parameter values
}

This article was published in the following Dove Press journal:

Patient Preference and Adherence

8 April 2015

Number of times this article has been viewed

\author{
Wanjie Yang' \\ Qingguo Feng' \\ Youzhong $\mathrm{An}^{2}$ \\ Xuefeng Zhao' \\ Kai Wei' \\ Chang $\mathrm{Li}^{\prime}$ \\ Wei Wang' \\ Hongyun Teng' \\ 'Department of Critical Care, The \\ Fifth Central Hospital of Tianjin, \\ Tianjin, People's Republic of China; \\ ${ }^{2}$ Department of Critical Care, The \\ People's Hospital, Peking University, \\ Beijing, People's Republic of China
}

Correspondence: Wanjie Yang Department of Critical Care, The Fifth Central Hospital of Tianjin, Tianjin 332400, People's Republic of China Tel/fax +86 220937428 I/432I

Email wanjie_yang@।63.com
Aim: To investigate the effects of differential sites for cold saline injection on transpulmonary thermodilution parameter values.

Methods: This was a prospective study. Twelve patients were recruited for the following examinations: control condition (injection site at proximal injection end of the Swan-Ganz catheter), proximal end condition (injection site at sheath of the Swan-Ganz catheter), and distal end condition (injection site at PA end of the Swan-Ganz catheter). Sixty measurements were performed for each condition. The cardiac index, global end diastolic volume index (GEDI), and extravascular lung water index for the three different injection sites were recorded from each patient. In addition, the mean transmission time (MTt), downslope time, and area under the curve obtained from PiCCO-VoLEF-Win software were compared among different groups.

Results: There were no differences in cardiac index and extravascular lung water index values among the three conditions $(P>0.05)$. There were no differences in GEDI between the proximal end condition and control condition $(P>0.05)$, while the GEDI was significantly lower for the distal end condition $\left(493.33 \pm 254.65 \mathrm{~mL} / \mathrm{m}^{2}\right)$ than for the control condition $\left(645.53 \pm 234.46 \mathrm{~mL} / \mathrm{m}^{2}\right)$ $(P<0.05)$ and proximal end condition $\left(717.96 \pm 321.63 \mathrm{~mL} / \mathrm{m}^{2}\right)(P<0.01)$. There were no differences in downslope time and area under the curve among the three conditions $(P>0.05)$. There were no differences in MTt between the proximal end condition and control condition $(P>0.05)$, while the MTt was significantly lower for distal end condition (40.22 \pm 16.37 seconds) than for the control condition $(42.91 \pm 17.93$ seconds $)(P<0.05)$ and proximal end condition (47.16 \pm 16.64 seconds) $(P<0.01)$.

Conclusion: The differential sites for cold saline injection impacted transpulmonary thermodilution parameter values.

Keywords: pulmonary artery catheter, global end diastolic volume index, extravascular lung water index

\section{Introduction}

The transpulmonary thermodilution parameters obtained from a pulse index continuous cardiac output (PiCCO) monitor are being employed more and more in clinical hemodynamics monitoring. However, the accuracy of transpulmonary thermodilution parameter measurement is affected by a series of factors, including the differential injection site for cold saline. A previous study examined the effect of the differential venous catheter site (internal jugular vein versus femoral vein) on transpulmonary thermodilution parameter measurement, ${ }^{1}$ yet there is no study on the potential effects when injection is made at differential sites of the superior vena cava. The present study examined the effects of cold saline injection at three different Swan-Ganz catheter sites on transpulmonary thermodilution parameter measurement. 


\section{Materials and methods \\ Clinical data}

This was a prospective study with 12 cases (eight males, four females; aged $23-76$ years, average $48.23 \pm 10.59$ years; height $151-182 \mathrm{~cm}$, average $170.63 \pm 23.34 \mathrm{~cm}$; weight $52-86 \mathrm{~kg}$, average $70.56 \pm 18.55 \mathrm{~kg}$ ) treated in the critical care department of our hospital from September 2012 to September 2014. All patients had a Swan-Ganz catheter and PiCCO thermodilution catheter placed at the same time. All patients were aged more than 18 years with no congenital heart disease, valvular heart disease, or other pulmonary vascular diseases.

The following three conditions were recorded: control condition (injection site at proximal injection end of the Swan-Ganz catheter), proximal end condition (injection site at sheath of the Swan-Ganz catheter), and distal end condition (injection site at PA end of the Swan-Ganz catheter) (Figure 1). Sixty measurements were performed for each condition and 180 sets of parameter measurements were recorded.

The study obtained approval from the ethics committee on medical research of The Fifth Central Hospital of Tianjin, Tianjin, People's Republic of China, and written informed consent was obtained from all patients.

\section{Monitoring approach}

All patients received Swan-Ganz catheter sheath placement to the right jugular vein, with the PA end connected to a

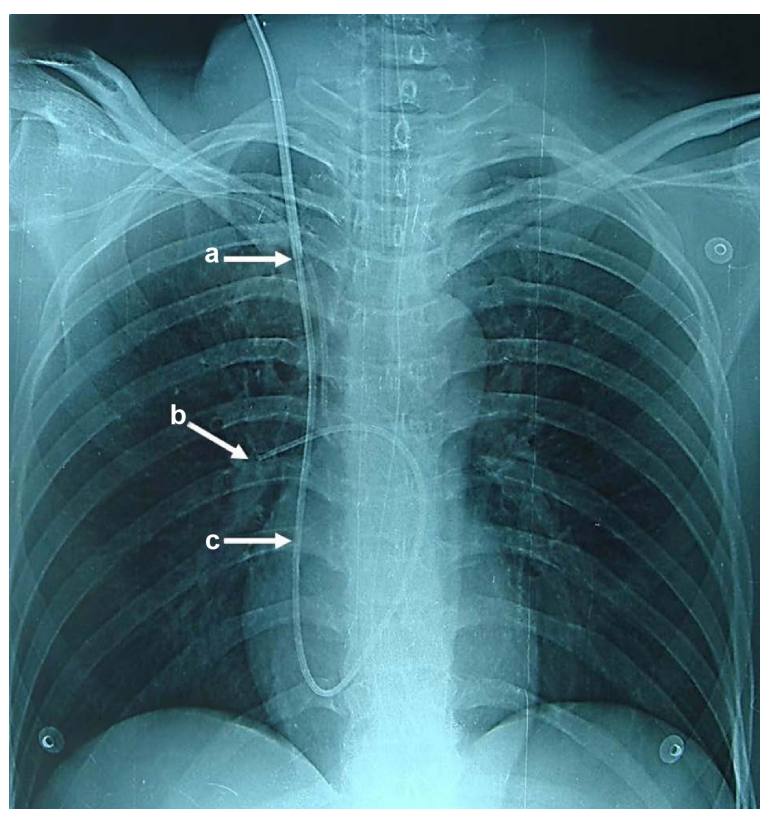

Figure I The different cold saline injection sites in the present study.

Notes: (a) Proximal end: sheath of Swan-Ganz catheter. (b) Distal end: PA end of Swan-Ganz catheter. (c) Control: proximal injection end of Swan-Ganz catheter.
Solar8000i monitor (GE Healthcare Bio-Sciences Corp., Piscataway, NJ, USA), followed by 7F Swan-Ganz catheter (Edwards Company, USA) placement into the sheath to obtain pulmonary artery pressure. The PV2014L16A transpulmonary thermodilution catheter (Pulsion Company, Germany) was placed into the left/right femoral artery and connected to a PiCCO plus volume monitor (Pulsion Company). The monitor was also connected to a computer installed with PiCCOVoLEF-Win software version 4.0 (Pulsion Company). The bedside lateral chest and pelvic $\mathrm{X}$-ray examinations were used to confirm the proper placement of the sheath end, Swan-Ganz catheter end, and transpulmonary thermodilution catheter end. Cold saline was injected at the Swan-Ganz catheter sheath, PA end of the Swan-Ganz catheter, and proximal injection end of the Swan-Ganz catheter, respectively, for transpulmonary thermodilution parameter measurements. Each injection contained $15 \mathrm{~mL}$ cold saline delivered in 4 seconds, and an average of all previous measurements was made based on three injections.

\section{Indexes recorded}

The cardiac index (CI), global end diastolic volume index (GEDI), and extravascular lung water index (ELWI) for three different injection sites were recorded from each patient. In addition, the mean transmission time (MTt), downslope time (DSt), and area under the curve (AUC) obtained from the PiCCO-VoLEF-Win software were compared among the different groups. Measurements were taken 30 minutes apart.

\section{Statistics}

The data were processed with SPSS 11.5 software and presented as mean \pm standard deviation. Analyses of variance were performed for differences among groups. $P<0.05$ was considered as statistically significant, and $P<0.01$ was considered as statistically very significant.

\section{Results \\ The transpulmonary thermodilution parameters}

The results of the transpulmonary thermodilution parameter measurements are presented in Table 1. There were no differences in $\mathrm{CI}$ and ELWI values among the three conditions (for CI: $P=0.12$ for control versus proximal; $P=0.15$ for distal versus control; $P=0.09$ for proximal versus distal. For ELWI: $P=0.11$ for control versus proximal; $P=0.13$ for distal versus control; $P=0.07$ for proximal versus distal). There were no differences in GEDI between the proximal end condition and control condition $(P>0.08)$, while the GEDI was significantly lower for the distal end condition 
Table I The transpulmonary thermodilution parameters with different sites of cold saline injection

\begin{tabular}{llllll}
\hline Condition & $\begin{array}{l}\text { Number } \\
\text { of cases }\end{array}$ & $\begin{array}{l}\text { Number of } \\
\text { measurements }\end{array}$ & Cl $\left(\mathbf{L} / \mathbf{m i n} / \mathbf{m}^{2}\right)$ & GEDI $\left(\mathbf{m L} / \mathbf{m}^{2}\right)$ & ELWI $(\mathbf{m L} / \mathbf{k g})$ \\
\hline Control & 12 & 60 & $3.75 \pm 1.34$ & $645.53 \pm 234.46$ & $9.36 \pm 3.43$ \\
Proximal end & 12 & 60 & $4.03 \pm 0.99$ & $717.96 \pm 321.63$ & $10.14 \pm 4.55$ \\
Distal end & 12 & 60 & $3.72 \pm 1.06$ & $493.33 \pm 254.65^{\mathrm{a}, \mathrm{b}}$ & $9.62 \pm 4.62$ \\
\hline
\end{tabular}

Notes: Control: injection site at proximal injection end of Swan-Ganz catheter; proximal end: injection site at sheath of Swan-Ganz catheter; distal end: injection site at PA end of Swan-Ganz catheter. ${ }^{a} P<0.05$ compared to control condition; ${ }^{b} P<0.01$ compared to proximal end condition. Data are presented as mean \pm standard deviation.

Abbreviations: $\mathrm{Cl}$, cardiac index; GEDI, global end diastolic volume index; ELWI, extravascular lung water index.

$\left(493.33 \pm 254.65 \mathrm{~mL} / \mathrm{m}^{2}\right)$ than for the control condition $\left(645.53 \pm 234.46 \mathrm{~mL} / \mathrm{m}^{2}\right)(P=0.03)$ and proximal end condition $\left(717.96 \pm 321.63 \mathrm{~mL} / \mathrm{m}^{2}\right)(P=0.002)$.

\section{The MTt, DSt, and AUC values}

The MTt, DSt, and AUC values are presented in Table 2. There were no differences in DSt and AUC among the three conditions (for DSt: $P=0.13$ for control versus proximal; $P=0.14$ for distal versus control; $P=0.10$ for proximal versus distal. For AUC: $P=0.11$ for control versus proximal; $P=0.14$ for distal versus control; $P=0.08$ for proximal versus distal). There were no differences in MTt between the proximal end condition and control condition $(P=0.07)$, while the MTt was significantly lower for the distal end condition (40.22 \pm 16.37 seconds) than for the control condition (42.91 \pm 17.93 seconds) $(P=0.02)$ and proximal end condition (47.16 \pm 16.64 seconds) $(P=0.001)$.

\section{Discussion}

The monitoring of hemodynamics in critical care patients has become very important in clinical management of these patients. PiCCO monitoring has been employed widely for CI, GEDI, and ELWI examinations. ${ }^{2,3}$ However, there can be errors in the parameters measured by PiCCO due to the limited approaches. For instance, measurement can be affected by the tidal volume in mechanical ventilation, positive end-expiratory pressure, extracorporeal membrane oxygenation, cold saline injection site, and reception sites. ${ }^{46}$ The cold saline injection site is important for the accuracy of transpulmonary thermodilution parameter measurements. In clinical practice, the tip of the catheter occasionally exhibits misplacement (Figure 2), leading to an altered site of cold saline injection and therefore disrupted parameter measurement.

According to the Stewart-Hamilton formula, cardiac output (CO) is mainly determined by blood temperature, injected solution temperature, and AUC. Since the AUC was not affected by the site of injection in the present study, the $\mathrm{CO}$ did not change significantly either. With Newman Mode, ${ }^{7,8}$ the volume $=$ time $\times \mathrm{CO}$. The time of blood stay in heart and lung during circulation was MTt, while the time for pulmonary thermodilution was DSt in the present study. Therefore, the intrathoracic thermal volume $($ ITTV $)=$ heart volume + pulmonary thermal volume $(\mathrm{PTV}) . \mathrm{ITTV}=\mathrm{MTt}$ $\times \mathrm{CO} ; \mathrm{PTV}=\mathrm{DSt} \times \mathrm{CO}$; ITTV $-\mathrm{PTV}=\mathrm{GEDV}$. Therefore, GEDV $=(\mathrm{MTt}-\mathrm{DSt}) \times \mathrm{CO}$. In the present study, the AUC and DSt did not show significant changes among the three conditions, therefore the GEDV differences were mainly determined by MTt. We found that the distal end condition exhibited significant changes from the control and proximal end conditions, suggesting that the placement of the catheter tip for cold saline injection warrants care.

The extravascular lung water (EVLW) measurement originated from the double indicator approach ${ }^{9}$ and has been obtained with the thermodilution approach in some studies. ${ }^{10,11}$ EVLW $=$ ITTV - intrathoracic blood volume $=$ PTV - pulmonary blood volume. In the present study, AUC and DSt did not change among the three conditions, therefore the PTV, determined by DSt $\times$ CO, did not change. In addition, the three conditions were measured in the same time period, with pulmonary blood volume maintained; therefore, EVLW did not show much change.

Table 2 The MTt, DSt, and AUC values with different sites of cold saline injection

\begin{tabular}{llllll}
\hline Condition & $\begin{array}{l}\text { Number } \\
\text { of cases }\end{array}$ & $\begin{array}{l}\text { Number of } \\
\text { measurements }\end{array}$ & MTt (seconds) & DSt (seconds) & AUC (seconds) \\
\hline Control & 12 & 60 & $42.91 \pm 17.93$ & $22.76 \pm 12.96$ & $6.56 \pm 2.32$ \\
Proximal end & 12 & 60 & $47.16 \pm 16.64$ & $24.17 \pm 12.32$ & $6.58 \pm 2.33$ \\
Distal end & 12 & 60 & $40.22 \pm 16.37^{\mathrm{a}, \mathrm{b}}$ & $23.33 \pm 12.34$ & $6.49 \pm 3.12$ \\
\hline
\end{tabular}

Notes: Control: injection site at proximal injection end of Swan-Ganz catheter; proximal end: injection site at sheath of Swan-Ganz catheter; distal end: injection site at PA end of Swan-Ganz catheter. ${ }^{a}<<0.05$ compared to control condition; ${ }^{b} P<0.01$ compared to proximal end condition.

Abbreviations: MTt, mean transmission time; DSt, downslope time; AUC, area under the curve. 

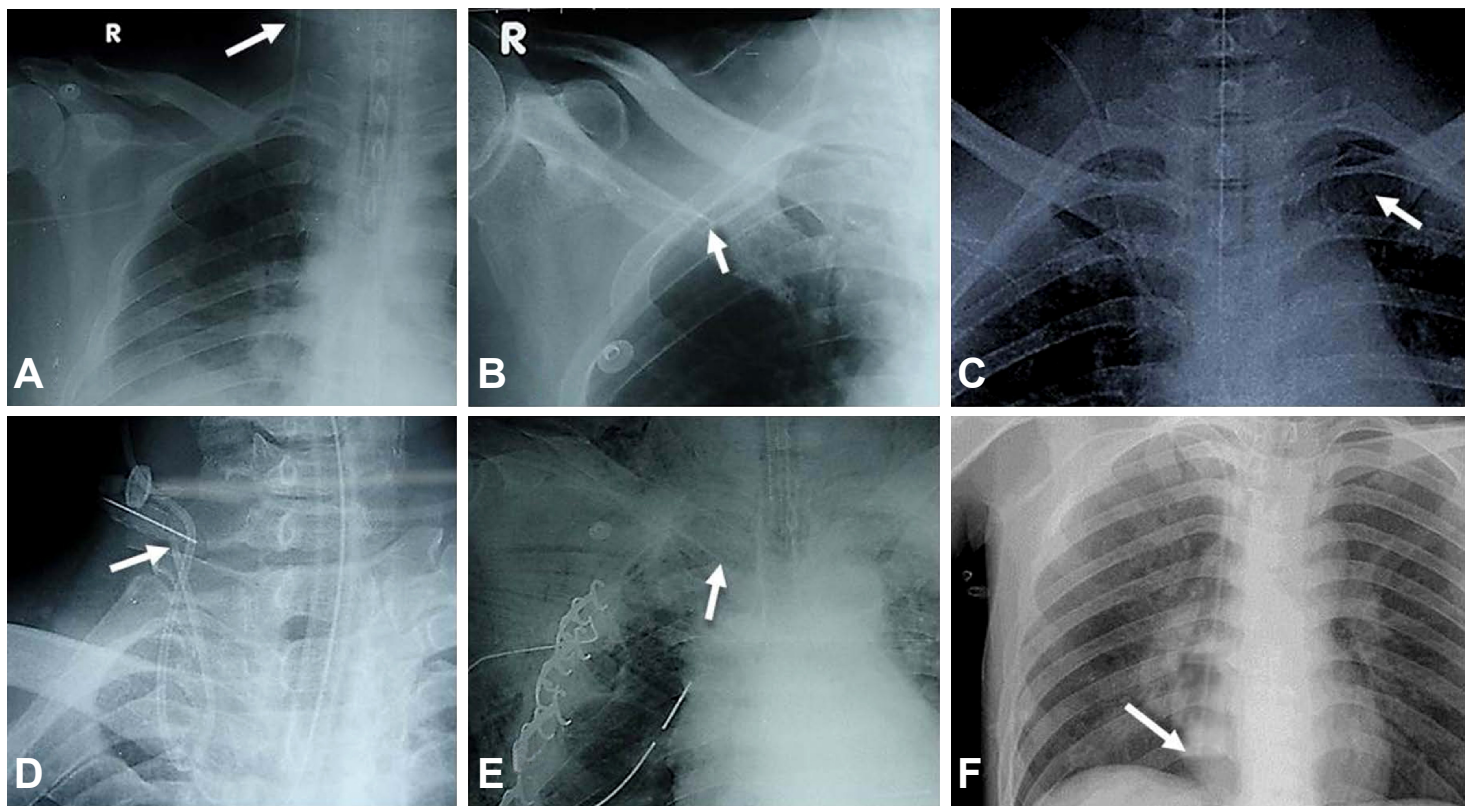

Figure 2 Several common misplacements of central venous catheter tips.

Notes: Arrows indicate the catheter tip positions. (A) Right subclavian vein catheter misplaced into the right internal jugular vein. (B) Right internal jugular vein catheter misplaced into the right subclavian vein. (C) Right internal jugular vein catheter misplaced into left jugular vein. (D) Catheter come back in right internal jugular vein. (E) Too-shallow position for a right subclavian vein catheter. (F) Too-deep position for a right subclavian vein catheter.

Abbreviation: $\mathrm{R}$, right.

In summary, the differential injection site of cold saline could affect the accurate measurement of volume parameters in transpulmonary thermodilution, but with little effect on $\mathrm{CO}$ and EVLW. In clinical management, the catheter tip should be placed correctly, and measurements recorded with a misplaced catheter should be judged with care.

\section{Disclosure}

The authors report no conflicts of interest in this work.

\section{References}

1. Schmidt S, Westhoff TH, Hofmann C, et al. Effect of the venous catheter site on transpulmonary thermodilution measurement variables. Crit Care Med. 2007;35(3):783-786.

2. Hofer CK, Furrer L, Matter-Ensner S, et al. Volumetric preload measurement by thermodilution: a comparison with transoesophageal echocardiography. Br J Anaesth. 2005;94(6):748-755.

3. Sakka SG, Reinhart K, Wegscheider K, Meier-Hellmann A. Comparison of cardiac output and circulatory blood volumes by transpulmonary thermo-dye dilution and transcutaneous indocyanine green measurement in critically ill patients. Chest. 2002;121(2):559-565.

4. Pinsky MR. My paper 20 years later: effect of positive end-expiratory pressure on right ventricular function in humans. Intensive Care Med. 2014;40(7):935-941.

\section{Patient Preference and Adherence}

\section{Publish your work in this journal}

Patient Preference and Adherence is an international, peer-reviewed, open access journal that focuses on the growing importance of patient preference and adherence throughout the therapeutic continuum. Patient satisfaction, acceptability, quality of life, compliance, persistence and their role in developing new therapeutic modalities and compounds to optimize
5. Pinsky MR, Desmet JM, Vincent JL. Effect of positive end-expiratory pressure on right ventricular function in humans. Am Rev Respir Dis. 1992; 146(3):681-687.

6. Sakka SG. Influence of an extracorporeal lung assist system on transpulmonary thermodilution-derived variables. Br J Anaesth. 2010; 104(5):664-665.

7. Meier P, Zierler KL. On the theory of the indicator-dilution method for measurement of blood flow and volume. J Appl Physiol. 1954;6(12): 731-744.

8. Newman EV, Merrell M, Genecin A, Monge C, Milnor WR, McKeever WP. The dye dilution method for describing the central circulation. An analysis of factors shaping the time-concentration curves. Circulation. 1951;4(5):735-746.

9. Goedje O, Seebauer T, Peyerl M, Pfeiffer UJ, Reichart B. Hemodynamic monitoring by double-indicator dilution technique in patients after orthotopic heart transplantation. Chest. 2000;118(3):775-781.

10. Nirmalan M, Niranjan M, Willard T, Edwards JD, Little RA, Dark PM. Estimation of errors in determining intrathoracic blood volume using thermal dilution in pigs with acute lung injury and haemorrhage. $\mathrm{Br}$ J Anaesth. 2004;93(4):546-551.

11. Sakka SG, Rühl CC, Pfeiffer UJ, et al. Assessment of cardiac preload and extravascular lung water by single transpulmonary thermodilution. Intensive Care Med. 2000;26(2):180-187.

\section{Dovepress}

clinical outcomes for existing disease states are major areas of interest for the journal. This journal has been accepted for indexing on PubMed Central. The manuscript management system is completely online and includes a very quick and fair peer-review system, which is all easy to use. Visit http://www. dovepress.com/testimonials.php to read real quotes from published authors. 